The book highlights the evolving nature of non-metallic biomaterials in dentistry. The reader is made mindful of the importance of acknowledging progress in the field and the value in responding to advances in the theory underpinning the method of tooth repair and replacements. This is a stimulating, informative read with a constructive purpose, delightful to study in its entirety and easy to dip into.

This book is a valuable addition to any dental library and is an essential reference for both undergraduate and postgraduate students, researchers and fully qualified dentists wishing to consolidate their appreciation of non-metallic biomaterials and keep abreast of advances in the field. It certainly encourages the current and future generations to investigate and prove these concepts and ideas wrong or to push them forwards.

P. Raphy

\section{ORAL AND MAXILLOFACIAL MEDICINE: THE BASIS OF DIAGNOSIS AND TREATMENT, 3RD EDITION}

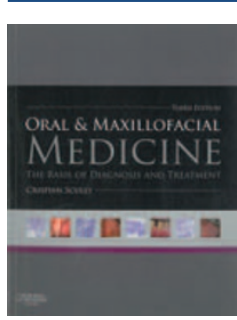

C. Scully

Churchill Livingstone

price £49.99; pp 448

ISBN 9780702049484

This is a fantastic and beautifully progressive book. However, it is no real surprise as Professor Scully's previous two editions excelled. The first edition was awarded first prize for a new authored book in 2004 by the Royal Society of Medicine and Society of Authors, and the second edition was highly commended in the British Medical Association Book Awards in 2009. It is fair to say he has not disappointed with a third edition. Ever open to suggestion, the author asked his readers for areas of improvement but was puzzled when he received none! Not wishing to accept this, the third edition is built on peer recommendations. It discusses cutting edge areas of adverse drug reactions and genetic influences in oral facial disorders.

The brilliance of this book for me is its accessibility. There are now clearly delineated 'learning aims and objectives' alongside the original 'intended learning outcomes'. These help those using this publication as a textbook. However, for clinicians wanting to utilise a quick, easy, accessible reference book complete with pictures and flow charts for ease of diagnosis then this book will prove valuable too.

For the busy GDP this book is a must for the bookshelf; it provides everything from handy, pull-out information for patients to history-taking and examination skills. Refreshingly, there are also useful mnemonics. For example, the causes of mouth ulcers can be remembered as the amusing, 'So Many Laws and Directives' standing for 'Systemic, Malignancy, Local and Drugs'. This allows for logical diagnosis and treatment planning.

Importantly, there is a new section dealing exclusively with cancers and potentially malignant disorders. This, coupled with the reordering of the already excellent material on common complaints and important orofacial conditions, instantly helps when deciding the urgency of any referral.

For those who find themselves in a hospital setting, the additional information regarding treatment agents is useful. The book also indicates a level of evidence when deciding on treatment agents for patients. This is important as many are prescribed 'off-label'. In addition to this the useful websites listed at the end of chapters provide an electronic extension for those wishing to explore the subject further.

This publication gives a unique insight into the wonderful mind of its author. It is the product of Professor Crispian Scully's many years of clinical and teaching experience, in the vast and varied field of oral and maxillofacial medicine.

\section{Porter}

\section{NOTHING BUT THE TOOTH:} A DENTAL ODYSSEY

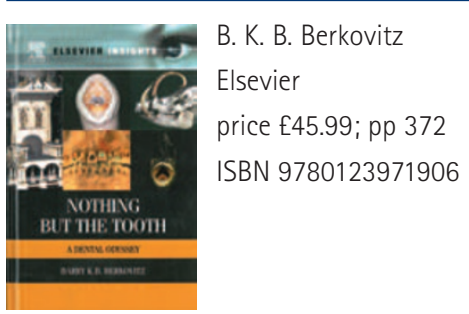

Nothing but the tooth: a dental odyssey is described by the author as a collection of information amassed throughout many years of research and teaching. I have read several of the author's books before and found his writing to be succinct, informative and conducive to learning. This book is no exception. From start to finish, it really is hard to put down. This may be because the book focuses mainly on dental topics that are not required to pass exams or influence clinical practice. The book takes the reader through a whole host of interesting dentally relevant areas and is not rivalled in any other text out there.

The book takes the reader through anatomical, anthropological and historical aspects of all things dental and everything in between. The author's passion and knowledge for his subject comes across with every turn of the page.

Chapters take you through the weird and wonderful dentitions of nature and how some more valuable forms were used for ornaments and decorative pieces. Topics covered include forensic testing related to the evolution of animals and locating origins of age old bodies dating back over 5,000 years.

Whilst the book is fascinating, I do, however, feel that it is lacking a little in some parts. The black and white photographs do not do justice to the text. Furthermore a lot of the anatomical photographs have no measure of scale to help the more uninformed reader. I realise some photos are rare and gifted for publication and cannot be altered but having colour where possible would really bring the most out of the book. I found one or two chapters a little hard going, most notably the highly scientific 'you are what you eat' section, which required a little perseverance. I knew a little about forensic dentistry from previous study and I felt this helped me through a long, perhaps slightly overcomplicated, section.

In summary, this book is crammed full of remarkable facts that make it a must read for anyone who has an interest in the broader subject matter. One never knows when the average weight of an elephant molar or which Nobel Prize winning dentists invented anaesthesia will come in handy. I highly recommend a read. 